\title{
DOSSIER
}

Mujeres y cultura en tiempo de crisis

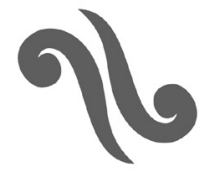





\title{
Un encuentro para la apropiación de la salud en mujeres campesinas de Chiltoyac, Veracruz
}

\section{A meeting for the appropriation of health in peasant women of Chiltoyac, Veracruz}

\author{
Citlalli Ramírez
}

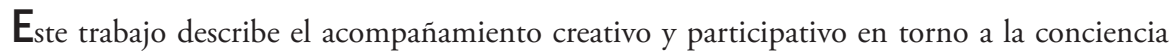
para la salud que se realizó con mujeres del Centro Comunitario de Tradiciones, Oficios y Saberes de Chiltoyac, Veracruz. La salud es un estado complejo. Requiere una visión transdisciplinaria para proponer pedagogías desde un orden sistémico y holístico, que considere a la mujer como sujeto y no como objeto de estudio. El objetivo era que reconocieran y se apropiaran de sus propios cuerpos como un proceso de deconstrucción de prácticas de orden patriarcal-colonialista-capitalista como una búsqueda de salud. Se utilizaron herramientas etnográficas, prácticas artísticas y de investigación-acción-participativa. Hubo tres etapas: 1) observación participante, 2) acompañamiento en la elaboración de un "Manual de herbolaria y medicina tradicional", y 3 ) un Taller de creación de una danza colectiva.

Palabras clave: arte, alienación, apropiación de la salud, transdisciplinariedad, género.

This article describes the creative and participatory accompaniment for health awareness that was carried out with women from the Community Center of Traditions, Trades and Knowledge in Chiltoyac, Veracruz. Health is a complex state, it requires a transdisciplinary vision to propose pedagogies from a systemic and holistic order, considering women as subjects and not as objects of study. The objective was for them to recognize and appropriate their own bodies as a process of deconstruction of patriarchal-colonialist-capitalist practices in search for health. There were three stages: 1) participant observation, 2) accompaniment in the elaboration of a "Manual of herbal medicine and traditional medicine", and 3) a Workshop to create a collective dance.

Key words: art, alienation, appropriation of health, transdisciplinarity, gender.

Fecha de recepción: 19 de febrero de 2021

Fecha de dictamen: 5 de abril de 2021

Fecha de aprobación: 3 de mayo de 2021 


\section{CONSTRUCCIÓN HEGEMÓNICA DE LOS CUERPOS DE LAS MUJERES}

Para este trabajo se realizó una reflexión teórica, metodológica y empírica sobre las formas de imposición que el modelo patriarcal-capitalista-colonialista instituye sobre los cuerpos de las mujeres que derivaron en mi proyecto de tesis titulado "La expresión corporal como camino para la apropiación de la salud en un grupo de mujeres de la comunidad rural de Chiltoyac, Veracruz". Desde esta perspectiva, se describe la problemática sobre los modos en que se constituyen los cuerpos, y las formas de reproducirlo y de alienarlo. Numerosas veces nos comportamos a partir de formas aprendidas que no corresponden a las necesidades propias del cuerpo, a su fisionomía, a su funcionamiento, a las maneras de aprehender, de sentir y escuchar nuestro interior. El hombre y la mujer se dejan influenciar por el medio social en el que se desenvuelven, condicionados a un dejar de ser, dejar de desear, para pertenecer. Muchas de nosotras crecemos conformando nuestro ideal femenino desde el ejemplo familiar, de lo que se vive en la escuela, de la experiencia en sociedad, desde distintas fuentes que se entretejen entre sí en un proceso complejo que se ha dado a lo largo de la historia, cuya identificación responde a lo que el sistema exige y conduce con la subordinación femenina, situación en la que se privilegia la idea de un mundo civilizatorio cuya fuerza mecaniza y fragmenta el cuerpo de las mujeres con sus consecuentes afectaciones a la salud. Esta concepción del cuerpo de la mujer como un constructo social, producto del androcentrismo, se acompaña de una condición aprendida o manipulada de los modos de producción y consumo del capitalismo que recaen sobre el cuerpo. Éste, como menciona Jean Baudrillard (2009:166), se encuentra vinculado con las finalidades de la producción "como soporte (económico), como principio de integración (psicológica) dirigida del individuo y como estrategia (política) de control social". Entre las consecuencias de la sociedad de consumo están los distintos padecimientos físicos, estrés, depresión; y las vinculadas con el cuerpo femenino, como la vergüenza, la anorexia o la presión estética, señaladas en los análisis de Sandra Lee Bartky y Susan Bordo (citadas en Amigot y Pujal, 2006:107). Procurar el autocuidado, la expresión o la escucha de sí mismas generalmente no forma parte de lo aceptado por las propias mujeres; lo anterior describe un desequilibrio entre la mente, el cuerpo, el espíritu y el lugar que habitamos, y se convierte en una práctica de vida, en la que muchos de los padecimientos físicos y mentales que nos aquejan se deben a esta desconexión y falta de atención.

Dejamos de mirarnos, evadimos comprender lo que somos, cómo sentimos, nuestra propia naturaleza, cuyas propiedades imaginativas, creadoras, armónicas, de goce y poetización del saber humano se reemplazan por seguir la "norma social", lo que la hegemonía nos enseña al objetivar los cuerpos. Es la perspectiva de género la que permite visualizar la alienación particular de los cuerpos de las mujeres dictada por un sistema 
sexo-género; y advierte que la sociedad y su cultura enmarcadas por una historia de violencia y opresión es la que conforma el ser mujer que incide en los "deber ser" corporales de la feminidad, lo que ha constreñido el desarrollo expresivo y holístico de los cuerpos femeninos. Ante estos problemas, retomo de Leonardo Boff (2002:30) la importancia esencial del cuidado: "Sin cuidado, deja de ser humano. Si no recibe cuidado, desde el nacimiento hasta la muerte, el ser humano se desestructura, se marchita, pierde el sentido y se muere". El cuidado parte de la conciencia de sí, para ésta, Hanna (1994:36) dice que "hay dos formas de ver al ser humano: desde el exterior o desde el interior", y esto lo explica del siguiente modo:

Cuando vemos otro ser humano, lo que miramos es un "cuerpo" con determinado tamańo y apariencia exteriores. Ocurre lo mismo que cuando observamos una estatua o una figura de cera que también tiene una forma y un tamaño "corporal"; pero cuando el ser humano se ve a sí mismo desde su interior, está consciente de sus sentimientos, de sus movimientos y de sus intenciones: un ser más distinto y más completo. Ver un cuerpo desde el exterior es tener un punto de vista de tercera persona: uno ve un "él" o una "ella" o una "cosa"; pero cuando un hombre o una mujer se observan desde su interior, tienen un punto de vista de primera persona: una imagen privilegiada del "yo", lo que significa tener conciencia "de sí mismo".

A partir del acto consciente, un cuerpo que siente, piensa y hace es capaz de resignificar y apropiar sus experiencias, un cuerpo viviente (Hanna, 1994). En el ampliar la mirada de lo que estamos haciendo, adquieren sentido el qué y el para qué de la vida desde su propia subjetividad que lo complementa. Un cuerpo que puede reconstruirse como un ser integrado en cuerpo-mente-espíritu-naturaleza, y generar salud para sí mismo y para su entorno. El término conciencia, según Guiber Mijares (2008:42-43), tiene que ver con una:

[...] triple concepción integrada de las dimensiones del cuerpo: 1) la conciencia del cuerpo como algo individual, es decir, como una experiencia fenoménica exclusiva del propio individuo; 2) la conciencia del cuerpo como algo social, como un símbolo que hace evidente la relación hombre, cultura y naturaleza, desde la relación con el otro y con el entorno; y 3) la conciencia del cuerpo política y metafórica, como una herramienta social y de control, pero también como un lenguaje, una propuesta ideológica. Estos tres niveles de conciencia del cuerpo logran vincularse entre sí mediante la emoción. Esta última es la mediatriz entre los cuerpos individual, social y político-metafórico, y es la que finalmente hace posible la valoración, de manera positiva o negativa, de los aspectos aprehendidos y concientizados en esta triple construcción. Los asuntos relacionados con la salud y la enfermedad son concientizados de esta misma manera. 
Desde esta propuesta, se supone romper las lógicas binarias, las del pensamiento positivista, al experimentar procesos de acompañamiento y espacios de indagación comprometida desde y con el cuerpo, además de reconocer otros cuerpos. En este sentido, podría decirse que la conciencia del movimiento es una acción que se experiencia. Todos necesitamos comunicar y expresar tanto nuestro bienestar como malestar, para lo segundo, sacar-liberar aquello que a la larga genera enfermedad. El desarrollo del estado consciente del cuerpo, además de propiciar una relación de sana armonía con éste, sucede consecuentemente con las relaciones sociales. "Cuidar es más que un acto, es una actitud. Por lo tanto, abarca más que un momento de atención, de celo y de desvelo" (Boff, 2002:1); sabiendo esto, ¿cómo se puede contribuir a desarrollar formas de cuidado y atención del propio cuerpo desde la expresión corporal?

El autoconocimiento del cuerpo conforma la base de nuestra salud, es por ello que el trabajo se centró en generar un proceso de descubrimiento en la persona, con la ayuda de la expresión corporal y de la educación somática para el trabajo de concientización corporal, y de esta manera crear un movimiento corporal acorde con el cuerpo somático, "lugar de experiencias múltiples y confluencia de múltiples ejes de sentido, diferenciación y reconocimiento: de lo físico, lo simbólico y lo social” (Payne, 1992:24). Al agregar el punto de vista somático a las ciencias humanas podremos superar las principales alteraciones de salud que aquejan a toda la humanidad (Payne, 1992:37). Así, por medio de la expresión corporal o movimiento creativo, "se enriquece esa expresión y lenguaje corporal al profundizar en la creatividad, la imaginación, la comunicación, etcétera” (Rodríguez, 2008:131-132) y se visualiza “[...] el medio que permite reconocer habilidades, destrezas y capacidades en escenarios de enseñanza aprendizaje, por medio de espacios creativos, llenos de imaginación, espontaneidad, goce e improvisación" (Blanco, 2009:16).

En la exploración epistemológica del arte para el trabajo con el cuerpo, entendí que era necesario concebir de manera diferente el concepto de salud a la definición institucionalizada y parcelaria de los saberes del cuerpo. En la salud son tan importantes y necesarios ciertos procesos de reconocimiento que se reflejan en la ampliación de las capacidades y/o habilidades físicas y mentales según la particularidad de cada persona, y tomo de los conceptos de salud de Diego Gracia Guillén (citado en Bermejo, 2006), quien se refiere a la salud como "capacidad de posesión y apropiación por parte del hombre de la propia corporeidad", y de José Bermejo (2006), quien reclama en el concepto de salud la autonomía y la responsabilidad, pues señala que la salud no depende exclusivamente de cómo se sienta el sujeto, sino más bien del modo como consiga vivir cada persona su realidad limitada. A lo que Torres (2008:70) añade "[...] la experiencia del arte, la acción creadora y el acto creador son en sí necesarios y saludables, por cuanto nos procuran anclajes con la vida, con nuestra propia biografía, 
con nuestro propio cuerpo que siente e imagina”. La salud implica, además, un trabajo de corresponsabilidad en el que la persona comience a ser consciente de sí y no depender sólo de lo que otro le pueda decir de sí mismo. Es así que las cuestiones kinestésicas, cognitivas, musicales, creativas, además de las fisiológicas, conforman el conjunto epistémico de nuestra salud. Como se dijo, este proceso, que pareciera se da de manera natural, en realidad requiere desarrollarse, por lo que además de un concepto propio de salud, se precisa, como se dijo, un enfoque distinto del cuerpo. Un acto de salud se da en las pautas para educar, o reeducar el cuerpo desde percibirlo más conscientemente hacia experimentar la creatividad. Para ello es pertinente la estrategia transdisciplinaria como una actitud que marca un quiebre con lo que nos aliena, en la que se reconoce al cuerpo como escenario de reflexión profunda sobre la complejidad de la realidad.

El trabajo con el cuerpo es complejo, como lo es la atención de un grupo de mujeres de una comunidad rural cuyo contexto general e historia de vida de cada quien conforman un entramado diverso e igualmente complejo. Desde la perspectiva de la transdisciplinariedad, los cuerpos se conciben en el contexto de la emergencia planetaria (Morin et al., 2002), de la crisis global de la era moderna, y del desencantamiento del mundo (Berman, 1987), frente a esto:

[...] la transdisciplinariedad es la apuesta por comprender la realidad que somos y nos constituye, cuando han sido puestas en paréntesis las barreras demarcatorias de las disciplinas y cuando la realidad ya no es vista como un "objeto" que está al frente de un sujeto y que se puede conocer de manera determinista (Osorio, 2012:17).

En un entorno donde la relación con la naturaleza y la falta de sentido se han perdido surge la pregunta: ¿hacia dónde va la humanidad? Y de ésta, reflexiono y se desprenden muchas otras más: ¡cómo nos construimos en este mundo, sobre qué bases, qué modelos seguimos, podemos seguir o proponer?, ¿`cómo generamos conocimiento?, ¿qué es conocimiento y para qué o para quiénes?, ¿el conocimiento sólo parte del pensamiento, o también del cuerpo y/o del espíritu?, ¿cómo apropiamos el conocimiento, el cuerpo?, ¿̨cuál es el sentido de lo que hacemos? Dichas interrogantes implican mirar desde y hacia el propio cuerpo en su proceso histórico y reconocer la no linealidad de la realidad. Justamente en este sentido es que la propuesta de la transdisciplinariedad trasciende la división sujeto-objeto que nos enajena o vuelve espectadores indiferentes (Pappenheim, 1974:21), y desde ésta, quien investiga se reconoce como parte del proceso de la investigación y de transformación mediante procesos experienciales, donde interactúan múltiples niveles de realidad, diversas historias de vida, concepciones, percepciones distintas de cada individuo involucrado. Yo nací y vivo en un área urbana, en mi formación académica y contexto de vida ha 
predominado la visión científica, dentro de la cual experimenté un apercibimiento de que "algo" no me correspondía; mi cuerpo me daba seńales de que lo había usado a favor de intereses ajenos; me hacía falta reconocerme en mi propio cuerpo y mirarme en mis semejantes. Me daba cuenta de los problemas que imperaban a mi alrededor como mujer, y al llegar a una comunidad rural, observé que no había separación; se trataba de una realidad compleja que me rebasaba en lo individual, en la que comencé a tomar en cuenta distintas realidades que se hacían presentes en cualquier contexto al que fijase la mirada, aun considerando sus características particulares, se asomaba el descubrir algo más allá de lo que la visión colonial-patriarcal-capitalista me ha enseñado a ver hasta entonces. La realidad se transforma todo el tiempo; en el inicio de un proceso transdisciplinario requerimos deconstruir el lenguaje que hasta ahora usamos para entrar en la actitud del no saber, y dirigirnos hacia la apertura de la curiosidad genuina; escuchar a la otredad para construir conjuntamente en una relación participativamente creativa entre el investigador y los implicados en una correspondencia uno a uno, sin jerarquías ni formas que nos despojen de nuestro ser humano.

\section{CHILTOYAC: BREVE SEMBLANZA DE UN PUEBLO CAMPESINO}

El contexto fue Chiltoyac, un pueblo precolombino de origen totonaca, situado en la cuenca cafetalera Xalapa-Coatepec, a ocho kilómetros al noreste de la capital del estado de Veracruz, México, en la zona rural del municipio de Xalapa. A lo largo de su historia, los pobladores han estado circunscritos en la lucha por el territorio bajo el principio básico "la tierra es para quien la trabaja" (Núñez, 2005:13). Sin embargo, los derechos agrarios de poseer títulos ejidales, en la mayoría de los casos, excluyen a las mujeres, aunque ellas conocen y han trabajado la tierra. En estas reglas sociales, al casarse, las mujeres se apartan de su familia origen para disponerse a los intereses de la nueva familia con el esposo, pues las suman a las prácticas y costumbres que toda mujer debe cumplir, como las labores del hogar, atender al marido, a los hijos y a los suegros, así como ajustarse a las formas de vida social, política y económica en las que la organización familiar se rige principalmente por los dueños del ejido.

En esta comunidad, siguen vigentes los saberes de la alfarería, la herbolaria, la medicina y la cocina tradicionales, así como prácticas culturales como la bendición del maíz, y su danza tradicional "El caballito del Señor Santiago", hecha e interpretada por hombres. Las celebraciones son de gran importancia para el pueblo, pues reafirman sus creencias, tradiciones y costumbres que se definen como parte de su identidad (Núñez, 2005). En las últimas décadas se vive una severa crisis agrícola y su efecto migratorio, características principales de los pueblos rurales de la región. En este sentido, la apertura 
comercial y su consecuente fenómeno de globalización neoliberal, ha destruido "[...] los mundos comunales, propiciando el incremento en la mercantilización de la vida y el cambio en los patrones de consumo" (Núñez y Castillo, 2020:16). Aunado a esto, en Chiltoyac se da un proceso de deterioro ambiental, sus ríos inmediatos se encuentran contaminados, sus afluentes de agua limpia se disminuyeron al entubarla, la construcción de un libramiento que pasa por encima del pueblo provocó diversas afectaciones a los cultivos, además de la venta de terrenos, su cercanía con la mancha urbana lo posiciona vulnerable por los rellenos sanitarios que comparten, cuyos lixiviados se filtran afectando en varios sentidos a la población. En este escenario diverso, en el que las mujeres de Chiltoyac se ven inmersas entre la tradición y las ideas de la modernidad y desarrollo, así como entre sus orígenes y la construcción social de la cultura influenciada por la participación del Estado, de los grupos representativos predominantemente masculinos, se constituyen las pautas para atender sus necesidades básicas desde el afuera, es decir, de lo que el sistema en curso dicta según las reglas del mercado y la configuración del Estado-nación que influye en las prácticas de salud y bienestar del pueblo.

\section{ACOMPAÑAMIENTO DE UN PROCESO DE DECONSTRUCCIÓN CON MUJERES CAMPESINAS}

En el 2012 se conformó el Centro Comunitario de Tradiciones, Oficios y Saberes en Chiltoyac (Cecomu), un proyecto transdisciplinario que articula actividades de docencia, investigación participativa y creación colectiva, impulsado por el Centro de EcoAlfabetización y Diálogo de Saberes de la Universidad Veracruzana y por la iniciativa de distintas instancias de organización local (Núnez y Castillo, 2020). Desde su creación, en este espacio se dibuja el interés de las mujeres de esta localidad por abordar el tema de la salud para atender las necesidades específicas reconocidas en el seno del Círculo de Mujeres. Después de seis años de trayectoria, comencé a colaborar con un proyecto participativo de investigación e intervención con 16 participantes mujeres de 21 a 63 años. El objetivo consistió en propiciar conciencia desde el propio cuerpo para generar una práctica de salud que las incluyera. Las estrategias metodológicas que se conjuntaron para propiciar el proceso de transformación social fueron: herramientas participativas y etnográficas, así como expresión corporal. Las primeras integran herramientas de la investigación acción participativa (IAP) como los círculos de diálogo, la acción participante, la acción colectiva, colaborativa, solidaria y la sistematización in situ. Las estrategias provenientes de la expresión corporal se sustentan en la atención del cuerpo, el movimiento, el juego, la espontaneidad, la libertad, la imaginación, la creatividad; y las etnográficas se enfocaron en la observación, entrevistas directa 
e indirecta y descripciones densas. Hubo tres etapas: 1) observación participante, 2) acompañamiento en la elaboración de un "Manual de herbolaria y medicina tradicional", y 3) un Taller de creación de una danza colectiva para experimentar los beneficios del movimiento creativo para la salud.

En la primera etapa, como observadora participante, me di a la tarea de conocer al Círculo de Mujeres del Cecomu, su historia y algunos trabajos colaborativos, a partir de pláticas y experiencias de trabajo como huertos, faenas comunitarias, alfarería, herbolaria, entre otras. Así como las de la dinámica social de la comunidad. Fue posible observar que las mujeres revelan diversas dificultades físicas para realizar movimientos, debido a que la mayoría se encuentra en la etapa de la edad adulta intermedia (40-65 años), lo cual implicó una tarea mayor al intentar eficientar los patrones de movimiento que prevalecen, como palmear las tortillas, lavar la ropa, caminar, respirar, agacharse, erguirse, chapear, descansar, etcétera. Se observó debilitamiento en espalda, abdomen, piernas, brazos y hombros correspondientes a su edad, algunas lo han dicho pero destaca el no prestarle atención a esos cambios físicos, debido a que, culturalmente, las mujeres en Chiltoyac no paran de realizar labores y atenciones sea la edad que tengan, a menos que alguna condición de salud les impidiera continuar. Casi todas son casadas, a esto se suma que siete de ellas son abuelas, la mayoría con doble y/o hasta triple responsabilidad, pues ha sido evidente una sobrecarga de trabajo pues la atención se centra en el hogar y en el cuidado de los hijos, aunque ya estén grandes y/o casados, y de padres ancianos. Pese al gran trabajo que realizan y la forma en que poco a poco se empoderan con algunas prácticas desde su participación en el Cecomu, he observado que las mujeres de Chiltoyac sufren procesos de sujeción y se les heredan/ imponen prácticas de vida no saludables que replican diariamente en su papel de ser mujer, cumplir en casa los roles tradicionales de una familia en Chiltoyac. Esto incluye, por ejemplo, acompañar y ayudar al esposo, al padre o al abuelo en el campo, y quedarse a cargo de la educación de los hijos, las tareas, llevarlos a la escuela, llevarles el almuerzo; procurar el descanso del marido después de su regreso laboral, entre muchas otras actividades, según la historia de cada mujer. Un contexto en el que existía una tendencia a tener más de cinco hijos, una mujer comentó que se era así porque el párroco de la iglesia decía: "Hay que tener los hijos que Dios mande", aunque el deseo personal fuese tener no más de dos. Esto, sin duda, genera condiciones de poca salud, casi imperceptibles o totalmente desvalorizadas por las propias mujeres. Por ejemplo, respecto de su cuerpo: la tensión visible en hombros, espaldas, brazos, manos, piernas y rostros que denotan rigidez, malformaciones óseas, producto de tener que atender todo menos a ellas mismas. Como las jorobas, los dedos torcidos o con artritis por pasar del calor al frío repentinamente, de hacer las tortillas a lavar la ropa, por ejemplo; caderas desbalanceadas, por el exceso carga de trabajo o tener muchos hijos, 
malas posturas para sentarse, agacharse, trabajar; incapacidad para reconocer el dolor, la incomodidad, el desgaste. En Chiltoyac es mal visto que una mujer, ya sea porque es viuda o abandonada, tenga iniciativas de recreación y/o búsqueda de su disfrute y desarrollo personal; esto se da en mayor medida que en mujeres que cuentan con pareja, pues las mujeres de la misma comunidad aluden juzgándolas y demandándoles lo que debieran hacer en su condición de mujer. A esta situación de sumisión en la vida cotidiana, se suman otras complejidades de violencia, abandono y alcoholismo a su contexto inmediato, situaciones que generan condiciones de vulnerabilidad en la salud tanto emocional como física. Se hizo evidente la falta de conocimiento sobre el propio cuerpo, predomina la creencia y esperan al que sabe para que les explique; esto se halló en la forma de hablar o dibujar al señalar sensaciones de cansancio o dolor poco descriptivas y/o generales en vez de específicas, que además se evidenciaba en las maneras de mover el cuerpo.

En la segunda etapa, me inserté en el acompañamiento de un proyecto de elaboración de un "Manual de herbolaria y medicina tradicional" en el que participaba el Círculo. Se revitalizaron los saberes que sus abuelas, madres y demás mujeres comparten con ellas sobre las propiedades de las plantas y sus usos para la salud. Se habló de las enfermedades recurrentes en la familia y de la salud de la mujer partiendo de la pregunta ¿qué es salud de la mujer? Lo que llevó a la reflexión y el compartir experiencias de vida en torno a los procesos naturales del ciclo de vida de las mujeres. Se hizo énfasis en por qué decir específicamente salud de la mujer, de lo que suelen enfermarse y de lo que se permiten enfermar, y se halló una relación muy estrecha entre enfermedad y violencia. Se compartieron experiencias de la relación entre hijasmadres-abuelas, y entre otras mujeres, con los varones en las que hubo un darse cuenta en la falta de atención del autocuidado. También se reconocieron saberes locales y tradicionales, así como las estrategias a las que recurren ante la falta de recursos para la atención de la salud. Las preguntas surgían de manera espontánea a partir de la curiosidad de las mismas mujeres. Lo que prevalecía era un tiempo para la escucha atenta, el compartir experiencias de vida y sus conocimientos sobre el tema.

Se elaboraron tinturas, jarabes y pomadas de las plantas seleccionadas de la región según el orden de enfermedades que querían atender, lo que se acompañaba de actividades somáticas, de creatividad corporal, juegos participativos, de atención y escucha con el objetivo de sensibilizar y concientizar y atender el cuerpo propio y de los otros como práctica de salud. El diálogo en torno a las diferencias entre la medicina tradicional y la medicina alópata e institucional conllevó a una revaloración de la herbolaria. Se llegó a la conclusión de la importancia de la preservación de la medicina tradicional como práctica de salud para la comunidad. 
Mi aportación acompañó al Círculo con la planeación de dinámicas de movimiento y ejercicios lúdicos, participativos y de educación somática para el cuerpo, al principio y/o al final de cada reunión y que estuviesen relacionados con los temas de cada sesión. En las dinámicas de grupo, mi colaboración buscaba propiciar el juego, la creatividad, la conciencia y expresión corporal como pilares para articular las actividades del Círculo de mujeres en torno a la salud, con el arte, es decir, como otra manera de vivir la experiencia de un sujeto integral. Durante las sesiones de diálogo, la corporalidad y las formas de expresión de las mujeres se transformaban al pasar de un estado anquilosado, con los cuerpos cruzados de brazos, las espinas dorsales curvas, las miradas agachadas, las bocas apretadas, los pies encimados, y de expresar sus saberes y sentires tímidamente, a mostrar confianza para hablar y expresar lo que les interesaba, al permitirse llorar, y ofrecer apoyo en lo posible. Y como todo proceso en el que se involucran las emociones para el darse cuenta de la historia de vida que las caracteriza, durante esta fase se atendieron dos episodios de crisis dentro del Círculo de Mujeres provocados por la tensión y afluencia de los recuerdos que surgían en sus relatos a la hora de compartir la palabra.

En la tercera etapa se desarrolló un Taller de creación de una danza colectiva, con el objetivo de experimentar los beneficios del movimiento creativo para la salud. Surgió por petición de unas mujeres del Círculo, en su interés de hacer "algo" por su cuerpo y en su deseo por tener una danza propia como los hombres con su danza de "El caballito". Participaron ocho mujeres incluyéndome, se programaron 14 sesiones más una presentación escénica. La finalidad del taller consistió en articular el lenguaje corporal por medio de la danza contemporánea, con la intención de desarrollar habilidades psicomotrices y de expresión corporal que permitan un desarrollo integral, ocupando la técnica de contacto-improvisación, una práctica que agudiza los sentidos, los reflejos y la forma de comunicarse con los demás a partir del movimiento, donde la escucha corporal resulta de mucha importancia en el trabajo con otras mujeres. Se apoyó de la educación somática para el reconocimiento corporal, su reflexión y conciencia por medio de los sentidos para relacionarse con el mundo cotidiano y onírico de las participantes; utilizando el movimiento como una forma de expresión, un modo de permitirse ser y bajo el principio IAP: reflexión-acción-reflexión (Moreno y Espadas, 2002, citado en Alberich, 2008) adaptado a la metodología de la expresión corporal. En la reflexión se consideró a la pregunta como medio de introspección personal para el proceso de concientización. Algunas variaban, tales como: ¿dónde estamos?, ¿cómo estamos?, ¿quiénes estamos?, ¿cómo está mi cuerpo?, ¿qué he dejado afuera de este espacio?, ¿qué ha venido conmigo?, ¿cómo me siento en este momento?, ¿cómo respiro?, entre otras. Además, se trabajó en el reconocimiento de su anatomía, de su expresión corporal, en propuestas para la salud a partir de la danza y la convivencia en trabajo 
tanto individual como en colectivo, sumamos la crítica y reflexión sobre la revaloración del cuerpo, el tiempo y el espacio. Evitamos seguir patrones predeterminados de danzas ya hechas, como usualmente se enseña/impone; por contraste, se propició la espontaneidad de las acciones partiendo de lo que se sabe, del humor del momento, de la imaginación moral, y que dio pauta a la co-creación escénica de una danza y del plan de las sesiones de trabajo, y se procuró estar atentas al sentir del proceso, el cual permitió avanzar al ritmo del grupo.

Se planteó realizar una presentación en conmemoración del sexto aniversario del Cecomu, el grupo de la danza de mujeres comenzó a dar forma y sentido al proceso creativo que había iniciado meses atrás. El tiempo fue de reflexión y, con ello, las preguntas generadoras: ¿¿de qué les gustaría hablar?, ¿cómo quisieran ser vistas las mujeres de Chiltoyac?, ¿qué les gustaría representar, rescatar de Chiltoyac?; "piensen en sus madres, abuelas y otras mujeres de este lugar". Se hicieron ver los elementos identitarios: una dijo querer ser una mujer alfarera, llevando barro, molerlo, darle forma, hacer comales. Otra dijo "hacer tortillas” pero prefería no pasar sola, “¿por qué no hacerlo en grupos?"; otra le contestó "yo paso contigo, también quiero hacer tortillas”, se dieron tiempo para discutir cómo las iban hacer, si como en la actualidad, con papel, o como antes, a palmadas, habría que recordar a quienes nos enseñaron y conseguir la mesa, llevar la masa o moler el maíz en metate. Unas mujeres dijeron que doña Hortensia elaborara el mole. "¿Está usted de acuerdo o requiere tiempo para pensar otra cosa?, es lo que usted quiera”. Dijeron por ahí: “QQue Crisantemo haga pan!”, “como ella decida, no como ustedes asignen", dije. "Pues yo no quiero que haya borrachos en el pueblo, ya me chocaron, verlos por donde quiera y a cada rato", expresó Crisantemo con un tono cansado y con fuerza a la vez. Me sorprendió porque la pregunta fue ¿qué quieren que haya?, pero ella reveló también lo que no se deseaba. No hay una sola respuesta a un problema, la creatividad expande las posibilidades de solución, se revela la emoción y el deseo se vuelve nuestra metáfora. Faltaba Azalea, se veía que estaba pensando y preguntaba a las demás “qué sería bueno?”, le daban ideas y yo también exponía las mías, "puede ser algo que hacía tú abuela, algo de antes", y entonces le resonó un tema que le ha significado una lucha desde hace un tiempo atrás, colaborando con grupos organizados, para volver a lavar ropa y bańarse en el río Sedeño. Entonces Azalea se dispuso a recordar lo que hacían en aquel tiempo en que las aguas del río estaban limpias, con gran emoción de estar en ese lugar cuando era niña. Éramos un Círculo de mujeres intercambiando sentires y escuchándonos unas a otras. Así, en medio de la conversación colectiva, recuerdo que les dije: "Vayan pensando, ¿qué elementos son necesarios para mostrar a la gente y poner en escena?". Ese día, no dejamos de movernos, calentamos un poco, hicimos algo de coordinación y ritmo, y sin pensar ya se estaba configurando la danza, ahora “¿tú qué propones?, ¿cómo la ves tú?, ¿qué más 
le añadimos?, ¿qué les parece esto?”, "pero con las señoras de la tercera edad hicimos esto...", "más la forma de la foto que me mostraste", "¿y qué vamos a llevar?", "pues unas canastas bien adornadas", "pero no hay música", "no importa, pero díganme, ¿qué ritmos les gustan?, ¿qué se imaginan?”. Estaban planeados tres días de montaje y ensayo simultáneo, que se convirtieron en seis, había mucha disposición y entusiasmo. Las señoras decían que había que repasar, hacerlo bien; "todavía no sale", señaló Gardenia un poco angustiada; unas decían una cosa, otras lo contrario, y yo participaba sutilmente dejando que se expresara el colectivo, les decía "mejor desde el principio y ahí vamos sintiendo". "Pues hay que mandar a hacer unas faldas", dijo Gardenia; "no todas tenemos esa posibilidad, con lo que tengamos está bien", señalé. Hortensia dijo que ella podía prestar seis faldas del grupo de adultos mayores con el que participa, quienes cada 16 de diciembre salen a festejar la rama; otras pensaban buscar la falda de su hija, aquella que usó para alguna festividad escolar, o ver qué podían encontrar, dije "traigan lo que puedan y aquí decidimos entre todas", "no gasten". Margarita señaló "¿Y de abajo?", Girasol dijo: "unos huarachitos o zapatos", a lo que Girasol respondió "pero a mí nunca me han comprado zapatos, siempre he andado de chanclas", "yo también de chanclas", añadió Hortensia; para mí, no había ningún problema, el sentido era resolver con lo que tenemos a nuestro alcance, y dije: "ah, pues si quieren descalzas", pero alguien expresó: "Si quieres te vas conmigo el sábado a Xalapa y te compro unos, aunque sean sencillos, si estás de acuerdo nos vemos para el camión de las diez, tú también, Hortensia, si quieres". Nos quedamos sorprendidas, yo le agradecí su gran gesto de solidaridad. Conseguimos las canastas e intencionadamente probamos varias canciones y diferentes espacios, "¿cuál va a ser la definitiva, y en dónde vamos a bailar?", preguntó Girasol. Sobre la música, les propuse que escucharan una canción que creó una amiga en estilo son jarocho, pues éste fue el ritmo que más les gustó. "Pero tú tienes que bailar con nosotras", me dijo Margarita, a lo que contesté: "yo pensaba que era sólo para ustedes”, “ipero sí estás aquí!”, me dijeron Gardenia y Girasol. Agradecí que me integraran.

Llegó la fecha del evento y las mujeres, aunque nerviosas, estaban firmes en el compromiso que habían hecho. La del mole llevó sus ingredientes: chiles, chocolate, galleta y demás bolsitas con especias, sobre una base de piedras y leña pondría una cazuela de barro con una muestra de mole preparado y su cuchara de madera. Las de las tortillas llevaban ladrillos - porque ellas así se acostumbraron-, igual con leńa y encima el comal tradicional de barro; portaban su mandil del diario, y en la cubeta, la masa. La alfarera llevaba cargando su barro, y vaya que pesaba, con sus demás cosas dentro de una canasta. La mujer que representaba al borracho, decía que también a ella le habían tocado alcohólicos como maridos. Fácilmente consiguió una camisa blanca de manga 
larga, vieja, rota y arrugada que combinaba con un pantalón ancho de mezclilla y un sombrero usado por su esposo, además de la botella con un palito de cañita, que para ese día había llenado de aguardiente. Todo era tal como es, hasta el jabón de la ropa, en su bandeja de lavar. Lo único que no pudimos traer a la vida fue ese sońado río, donde una de las señoras añoró volver a bañarse y lavar su ropa en él; lo reemplazamos simbólicamente por una tela larga de color azul. Y yo, aunque un tanto incómoda por el papel de agente especulador que las mujeres me habían asignado, simulé en la compra de los terrenos, la astucia para convencer de lo que más tarde fue un despojo.

Cuando nos anunciaron como "El grupo de danza de mujeres", comprendimos que habíamos conformado un grupo, apoyado por las y los demás partícipes del Cecomu: su Círculo de mujeres, los señores de los adobes, los de la danza de "El caballito", los que ayudan en la parcela, el equipo de la Universidad Veracruzana, los estudiantes que coincidimos ahí, y fuimos albergados para crecer. Una comunidad que se gestó por la suma de esfuerzos, para propiciar un espacio que permitiera la convivencia, el diálogo y la reflexión. Al final del acto escénico el aplauso fue contundente y pronunciado. La crítica no se hizo esperar, el taller de danza resultó ser una práctica de pedagogía decolonial en la Casa Ejidal, porque a partir de una práctica educativa no formal como la intervención escénica, se logró compartir una experiencia de aprendizaje colectivo utilizando herramientas de las artes escénicas. Además en resistencia, porque buscó la participación, suscitó la creatividad junto con el pensamiento crítico de una realidad compleja que dio paso a una práctica empoderadora de las mujeres ante los ojos de su propia comunidad. La experiencia de darse cuenta de un cuerpo que puede expresar lo que somos y lo que no queremos ser. Darse cuenta emerge de la necesidad, ya sea la sensación de vacío o de hallar otras maneras de desarrollarse. Estas mujeres y yo, ahora somos nosotras, por habernos implicado en el diálogo y la escucha, en el esfuerzo y trabajo constante, por la autoconstrucción y afirmación propias. Somos cuerpos diversos, un cuerpo que hace frente a los constructos sociales que impiden nuestro despertar, lo que nos ha determinado sin preguntarnos. Con la capacidad de renacer, de crear herramientas que le darán sentido a la vida misma, de la posibilidad de heredar a otras mujeres lo que nos fue negado en nuestro cuerpo sagrado. Haberse permitido salir de sus casas, aunque sus maridos se enojaran, además de ser señaladas por otras mujeres que les decían: “¿para qué vas?, ¿qué, no tienes qué hacer?, no atiendes bien a tu marido, ni a tus hijos, sólo vas a perder el tiempo, ni que te pagaran por ir”. Además, a partir de este trabajo se ha permitido la expresión por medio del movimiento en un contexto de silenciamiento corporal. 


\section{REFLEXIONES FINALES}

El ejercicio de esta investigación acción participativa implicó consolidar prácticas pedagógicas para deconstruir las diversas formas de enajenación y opresión que prevalecen en los cuerpos de las mujeres. Durante el transcurso del tiempo hubo cambios en el aspecto físico de las mujeres. Comenzaba a haber una actitud de cuidado personal, en la que preguntaban al grupo qué era bueno para los dolores específicos, y/o con qué alimentos y/o plantas complementar para recuperarse de mejor manera. La soltura del cuerpo también comenzaba a visibilizarse, los juegos ayudaron mucho, pues se manifestó un espíritu que las divertía incansablemente, con lo cual sudaban, reían y gozaban, y el calor generado les permitían realizar los estiramientos y verse entusiasmadas, además de las cuestiones químicas y neuronales que produce el goce del movimiento. El diálogo se dio con el hablar del cuerpo, al mostrar las diversas formas de utilizarlo. Esto posibilitó experimentar la ampliación del movimiento y de la emoción desde la empatía y la confianza, lo que permitió contribuir a la conciencia del cuerpo por medio de la danza para lograr:

1. Conocer el propio cuerpo.

2. Ser consciente de él y de esta manera ser consciente del de las demás participantes, así como del entorno.

3. Propiciar la expresión de los malestares físicos y mentales a partir del cuerpo, y en el proceso de darse cuenta de la imposibilidad de expresarlos con palabras.

4. Favorecer la creatividad tanto individual como colectiva, no sólo como medio de expresión, sino también para construir nuevas formas de pensar y de sentir en torno al bien común y, por lo tanto, generar la experiencia de "comunalidad", que, de acuerdo con Víctor Toledo (2015), permite a las comunidades enfrentar y resolver retos y problemas tanto históricos como actuales.

La salud es un estado complejo que requiere una visión transdisciplinaria para proponer otras maneras de conocer y hacer, desde un orden sistémico y holístico, posicionando a la mujer como un ser integral. Lo que me llevó a comprender que el concepto de salud se debiera definir de acuerdo con las especificidades socioculturales de una comunidad y de acuerdo con el entramado de las realidades que una persona vive. Pareciera utópico pensar programas de salud que consideren tales perspectivas, sin embargo, creo que el trabajo con y desde el arte puede contribuir a la atención de las subjetividades hacia un camino coherente con las necesidades propias para la atención de la salud contrahegemónica. 
La creatividad es entonces un acto de resistencia, una manifestación que grita a través de los diferentes cuerpos. Para poder llegar a los encuentros con otras mujeres, para compartir un tiempo y espacio donde se crean nuevas dinámicas de relacionarse hacia el compartir la palabra que cura, el saludo que apapacha, las ideas que nos confrontan no sólo como mujeres sino también como seres humanos que se reconocen a sí mismos ante la emergencia de la crisis civilizatoria actual de la que hablan Edgar Morin, Basarab Nicolescu, Gustavo Steva, Toledo, entre otros. El diálogo de saberes nos fortalece, el trabajo con el cuerpo nos sitúa y apoya a reconocernos. Esto es muy complejo, porque como dije, es histórico, además Bohm (2001:10-11) explica que "de no ser por los 'bloqueos' conservados por la propia cultura, la creatividad latente de cada persona podría expresarse hasta un grado mucho más allá de lo que en general se considera”, es por ello que el trabajo corporal debiera continuar hasta volverse una segunda naturaleza.

Trabajar con mujeres me permitió entender la importancia de los procesos de educación acompañados que requieren de su correspondiente socialización; se trata de una comunidad de aprendizaje donde se generan acciones de liberación. Espacios para que las mujeres se reúnan y puedan apropiarse de su cuerpo, de su voz, de su mente y espíritu. Walter Mignolo (citado en Albán, 2017:7) habla de "comunidades donde se trabaja para vivir y no se vive para trabajar y consumir", en las que "la tarea del hacer, pensar y estar siendo decolonial es la sanación de la herida y de la viciosa compulsión hacia el 'querer tener", desprendernos de las normas y jerarquías modernas es el primer paso hacia el re-hacernos. Aprender a desaprender para re-aprender a valorarnos.

Mi intervención ha sido un camino al andar, como dijo Berman, por no estar inscrita en un modelo predeterminado de investigación; más bien acompañé atenta a construir lo posible con lo que se tenía, y me di cuenta de los impulsos creativos que se pronuncian por un mundo que anteponga el sentido de la vida por encima de banalidades y desesperanza. Hoy me concibo diferente, con múltiples experiencias de vida que acompañan mis sentires y saberes. Cuidarse es un acto revolucionario, es un acto político porque la tendencia del sistema capitalista es una pulsión de muerte; entonces, como dice Enrique Dussel, cualquier política que defienda la vida en estos tiempos, es una política revolucionaria y de resistencia. Esto es lo que debemos hacer, seguir trabajando para cuidarnos. El cuidado colectivo, el cuidado desde la comunidad cobra hoy una pertinencia fundamental. 


\section{RAMÍREZ UN ENCUENTRO PARA LA APROPIACIÓN DE LA SALUD EN MUJERES CAMPESINAS}

\section{REFERENCIAS}

Albán, A. (2017). Prácticas creativas de re-existencia basadas en lugar: más allá del arte... el mundo de lo sensible. Ciudad Autónoma de Buenos Aires: Del Signo.

Alberich, T. (2008). "IAP, redes y mapas sociales: desde la investigación a la intervención social”, Portularia, VIII (1), pp. 131-151 [http://revista-redes.rediris.es/webredes/portularia/08. Tomas_Alberich_Nistal.pdf].

Amigot, P. y M. Pujal (2006). "Ariadna danza: lecturas feministas de Michel Foucault", Athenea Digital (9), pp. 100-130 [http://atheneadigital.net/article/viewFile/n9-amigot-pujal/263-pdf-es].

Basaglia, F. (1985). Mujer, locura y sociedad. México: Colección la mitad de mundo.

Baudrillard, J. (2009). La sociedad de consumo: sus mitos, sus estructuras. Alicia Bixio (trad.). España: Siglo XXI Editores.

Beauvoir, S. (1949). El segundo sexo: los hechos y los mitos. Siglo XX Editores.

Berman, Morris (1987). El reencantamiento del mundo. Chile: Cuatro vientos.

Bermejo, J.C. (2006). "Qué es la salud” [https://www.josecarlosbermejo.es/que-es-la-salud/], fecha de consulta: 3 de octubre de 2019.

Blanco, M. de J. (2009). "Enfoques teóricos sobre la expresión corporal como medio de comunicación y expresión”, Horiz. Pedagógico, 11 (1), pp. 15-28 [https://dialnet.unirioja.es/ servlet/articulo?codigo=4892962], fecha de consulta: 12 de marzo de 2017.

Boff, L. (2002). El cuidado esencial. Ética de lo humano, compasión por la Tierra. Juan Valverde (trad.). Madrid: Trotta.

Bohm, D. (2001). Sobre la creatividad. Barcelona: Editorial Kairós.

Camacho, C.I. (2020). "Conformación, transformación y resistencias de un sistema biocultural alimentario. El caso de Chiltoyac, Xalapa, Veracruz", tesis de doctorado en desarrollo rural. México: Universidad Autónoma Metropolitana, Unidad Xochimilco.

Eisner, E. (2004). El arte y la creación de la mente: el papel de las artes visuales en la transformación de la conciencia. Espańa: Paidós Iberica.

Guiber, M. (2008). "La valoración de la salud desde la conciencia corporal en la enseñanza universitaria", Sinopsis Educativa. Revista Venezolana de Investigación, 8(1), pp. 39-50 [http://revistas.upel.digital/index.php/sinopsis_educativa/article/view/3513/1698], fecha de consulta: 10 de enero de 2018.

Hanna, Thomas (1994). Conciencia corporal. México: Editorial Yug.

Korol, C. (comp.) (2016). Feminismos populares. Pedagogías y políticas. Buenos Aires: América Libre, Chirimbote y El colectivo.

Lagarde, M. (2015). La mujer: sujeto histórico, sujeto del conocimiento. Los cautiverios de las mujeres. Madresposas, monjas, putas, presas y locas. México: Siglo XXI Editores.

Lederach, J.P. (2016). La imaginación moral: el arte y el alma de la construcción de la paz. Teresa Toda (trad.). Bogotá: Semana Libros.

Morin, E., E.R. Ciurana y R. Domingo (2002). Educar en la era planetaria. El pensamiento complejo como Método de aprendizaje en el error y la incertidumbre humana. Salamanca: IIPCUniversidad de Valladolid-USAL-Unesco. 
Muñoz, B., B. Rivero y A. Fondón (2013). "Feminidad hegemónica y limitación a la práctica deportiva. Universidad de Extremadura”, Feminismo/s, núm. 21, pp. 37-50 [https://rua.ua.es/ dspace/bitstream/10045/39684/1/Feminismos_21_03.pdf], fecha de consulta: 9 de junio de 2018.

Nicolescu, B. (1996). La transdisciplinariedad. Manifiesto. París: Ediciones Du Rocher.

Núnez, M.C. (2005). Ejido, caña y café. Política y cultura campesina en el centro de Veracruz. Xalapa: Universidad Veracruzana.

Núñez, M.C. e I. Castillo (2020). Reinventando sentidos comunitarios. Una experiencia de colaboración transdisciplinaria en una localidad campesina del centro de Veracruz. Xalapa, Veracruz: Universidad Veracruzana.

Osorio García, Sergio Néstor (2012). Ciencias de la complejidad, pensamiento complejo y conocimiento transdisciplinar. Re-pensando la Humana Coditio en un mundo tecnocientifico. Colombia: Universidad Militar Nueva Granada [http://cetr.net/files/1363793636_10_sosorio. pdf].

Pappenheim, F. (1974). La enajenación del hombre moderno. México: Serie Popular Era.

Payne, H. (ed.) (1992). Dance Movement Therapy: Theory and practice. Londres/Nueva York: Routledge.

Ramírez, C. (2021). "La expresión corporal como camino para la apropiación de la salud en un grupo de mujeres de la comunidad rural de Chiltoyac, Veracruz", tesis de maestría en salud, arte y comunidad. Xalapa, Veracruz: Universidad Veracruzana.

Rodríguez Barquero, Vivian (2008). "El mejoramiento de la salud a través de la expresión corporal: un enfoque holístico”, Reflexiones, núm. 87 (1), pp. 127-137 [https://revistas.ucr. ac.cr/index.php/reflexiones/article/view/11490].

Rodríguez, V. (2010). “Terapias artísticas: una alternativa para la persona adulta mayor en costa Rica”, Anales en Gerontología, núm. 6, pp. 85-98 [https://revistas.ucr.ac.cr/index.php/ gerontologia/article/view/8873/8353], fecha de consulta: 17 de diciembre de 2019.

Toledo, V. (2015). “Comunalidad: el poder subversivo de la cooperación”, La Jornada, 27 de octubre [www.jornada.unam.mx/2015/10/27/opinion/016a1pol], fecha de consulta: 13 de diciembre de 2019.

Torres García, Oscar (2008). “¿Por qué enseñar arte?”, Armas y Letras, 71(1), pp. 70-72 [http:// armasyletras.uanl.mx/71/16.pdf]. 

Mi cuerpa no es un templo,

es un territorio vivo y rebelde...

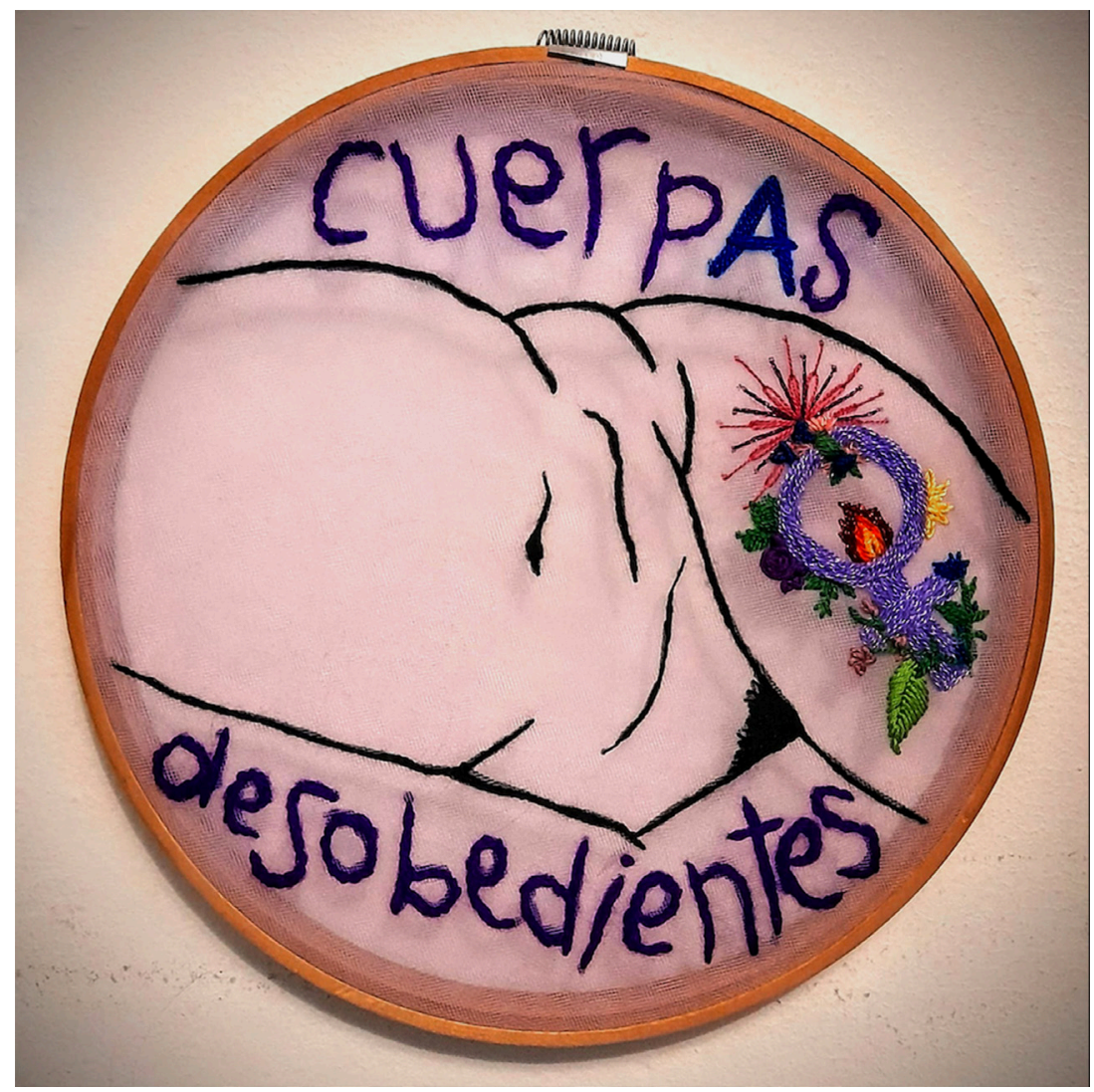




\section{Alejandra Collado | Cuerpas desobedientes}

Bordado en tul (agosto 2021) 